\title{
PRÁTICAS CONTEMPORÂNEAS DE MARKETING: O CASO DE PEQUENAS EMPRESAS DE CONFECÇÃO DE VESTUÁRIOS
}

\author{
1 Jackson Cittadin \\ 2 Aléssio Bessa Sarquis \\ 3 Ricardo Limongi França Coelho \\ 4 Nadia Kassouf Pizzinatto
}

\section{Resumo}

Objetivo: analisar pequenas empresas de confecção de vestuários quanto à utilização de práticas contemporâneas do marketing interativo, digital e de rede.

Metodologia: o estudo tem natureza qualitativa e descritiva, envolvendo multicasos, e foi conduzido por meio de entrevista semiestruturada, do levantamento documental e da observação direta.

Principais resultados: a pequena empresa de confecção de vestuários utiliza práticas de marketing de interação, de rede e, principalmente, digital, inclusive, com planejamento, avaliação de desempenho e intensidade, variando em função das orientações empreendedora e para o mercado.

Contribuições teóricas/metodológicas: discussão sobre práticas contemporâneas de marketing, no contexto de pequenas empresas de confecção de vestuários, e formulação de novas proposições de pesquisa.

Relevância/originalidade: tendo em vista que os estudos sobre a temática de práticas contemporâneas de marketing estão concentrados, em geral, no contexto de grandes organizações, este estudo considerou relevante discutir tais práticas também em pequenas empresas, de bens manufaturados, no Brasil.

Palavras-chave: Práticas contemporâneas de marketing. Marketing digital. Marketing interativo. Marketing em rede. Pequenas empresas.

Recebido: 22/04/2019 / Aprovado: 17/02/2020

Editor responsável: Profa. Dra. Vânia Maria Nassif

Processo de avaliação: Double Blind Review

Doi: https://doi.org/10.14211/regepe.v9i3.1547

\footnotetext{
${ }^{1}$ Faculdade Senac Criciúma - SENAC, Santa Catarina, (Brasil). E-mail: jacksoncittadin911@hotmail.com Orcid id: https://orcid.org/0000-0001-6466-5464

${ }^{2}$ Universidade do Sul de Santa Catarina - UNISUL, Santa Catarina, (Brasil). E-mail: alessio.sarquis@gmail.com Orcid id: http://orcid.org/0000-0001-9690-0510

${ }^{3}$ Universidade Federal de Goiás - UFG, Goiás, (Brasil). E-mail: ricardolimongi@gmail.com Orcid id: https://orcid.org/0000-0003-3231-7515

${ }^{4}$ Universidade Metodista de Piracicaba - UNIMEP, São Paulo, (Brasil). E-mail: nkp@nadiamarketing.com.br Orcid id: https://orcid.org/0000-0003-1598-6231
} 


\title{
CONTEMPORARY MARKETING PRACTICES: THE CASE OF SMALL CLOTHING MANUFACTURING COMPANIES
}

\begin{abstract}
Objective: to analyze small clothing manufacturing companies and the use of contemporary marketing practices in the dimensions of interactive marketing, digital marketing, and network marketing.
\end{abstract}

Methodology: the study is qualitative, descriptive and has multiple cases, and it is conducted through semi-structured interviews, documentary surveys and direct observation.

Main results: the small clothing manufacturing company uses interaction marketing practices, network marketing and mainly digital marketing, including some planning performance evaluation, and, intensity, varying according to the entrepreneurial orientation and marketing orientation.

Theoretical/methodological contributions: discussion of contemporary marketing practices, in the context of small clothing manufacturing companies, and formulation of new research proposals.

Relevance/originality: studies on theme of contemporary marketing practices are concentrated in the context of large companies, thus, this study discusses practices in the Brazilian context, small business, and manufactured goods.

Keywords: contemporary marketing practices; digital marketing; interactive marketing; networking marketing; small business. 


\section{PRÁCTICAS DE MARKETING CONTEMPORÁNEO: EL CASO DE LAS PEQUEÑAS EMPRESAS DE FABRICACIÓN DE ROPA}

\section{Resumén}

Objetivo: analizar pequeñas empresas de fabricación de ropa y el uso de prácticas de marketing contemporáneas en las dimensiones de marketing interactivo, marketing digital y mercadeo en red.

Metodología: el estudio es cualitativo, descriptivo y tiene múltiples casos, y se realiza a través de entrevistas semiestructuradas, encuestas documentales y observación directa.

Resultados principales: la pequeña empresa de fabricación de ropa utiliza prácticas de marketing de interacción, mercadeo en red y principalmente marketing digital, incluida alguna evaluación de desempeño de planificación e intensidad, que varía de acuerdo con la orientación empresarial y la orientación de marketing.

Contribuciones teóricas/metodológicas: discusión de prácticas de marketing contemporáneas, en el contexto de pequeñas empresas de fabricación de ropa, y formulación de nuevas propuestas de investigación.

Relevancia / originalidad: los estudios sobre el tema de las prácticas de marketing contemporáneas se concentran en el contexto de las grandes empresas, por lo tanto, este estudio analiza las prácticas en el contexto brasileño, las pequeñas empresas y los productos manufacturados.

Palabras clave: prácticas de marketing contemporáneas; publicidad digital; marketing interactivo; mercadeo en red; pequeños negocios. 


\section{INTRODUÇÃO}

A literatura sobre marketing na pequena empresa (PE) foi inicialmente elaborada a partir da prática e da gestão de médias e grandes empresas (Levit, 1975; Kotler, Armstrong, Harker, \& Brennan, 1990), mas os estudos evoluíram e ampliaram essa compreensão, sobretudo quanto ao ambiente do mercado contemporâneo, caracterizado pelo avanço da internet e de outras tecnologias, surgidas nos anos 2000 (Coviello, Winklhofer, \& Hamilton, 2006; O’Dwyer, Gilmore, \& Carson, 2009; CroninGilmore, 2012; Naudé, Zaefarian, Tavani, Neghabi, \& Zaefarian, 2014).

O termo "práticas contemporâneas de marketing" (PCM) compreende o conjunto de técnicas e de métodos modernos, aplicados pelas organizações na promoção de produtos/marcas e no relacionamento com os clientes e o mercado (Coviello, Milley, \& Marcolin, 2001; Reid, 2008; Parsons, Maclaran, \& Chatzidakis, 2017). Segundo Coviello et al. (2001), as PCM constituem uma abordagem de marketing, direcionada à construção de relacionamentos de longo prazo com clientes, e baseada no uso das tecnologias da informação, da comunicação e digitais. Assim, o marketing contemporâneo abrange métodos/táticas de marketing que transcendem ao tradicional mix de marketing e às práticas utilizadas no ambiente off-line.

Coviello, Brodie e Munro (1997) propuseram um modelo conceitual de PCM, conforme a perspectiva relacional, contendo as dimensões: marketing digital, marketing interativo e marketing de rede. O modelo, atualizado posteriormente por Coviello et al. (2001) e Reid (2008), foi testado por pesquisadores em diferentes contextos (Coviello et al., 2006; Dadzie, Jonhnston, \& Pels, 2008; Hapenciuc, Pînzaru, Vătămănescu, \& Stanciu, 2015;;Sarquis, Hoeckesfeld, Cittadin, \& Lenzi, 2019), tendo sido identificada a sua adequação para a análise em PE, inclusive no setor de bens manufaturados.

A discussão sobre o tema PCM é, então, crescente e diversificada, sendo que, no âmbito de PE, Taiminen e Karjaluoto (2015) identificaram práticas de marketing digital (e fatores que influenciam a sua adoção), em PE da Finlândia; e, no Brasil, Sarquis et al. (2019) revelaram o uso do marketing de interação (dentre outros) pela maioria das PE de contabilidade estudadas, até mesmo com o uso de métricas de desempenho de marketing.

A literatura sobre essa temática está direcionada às organizações de médio e grande porte, havendo, por isso, poucos estudos em países de economia em 
desenvolvimento e em setores de bens manufaturados, como a indústria de confecção de vestuários, cuja relevância econômica e social no Brasil é notória. Santa Catarina, por exemplo, ela responde por $25 \%$ da mão de obra empregada e por $16 \%$ do Produto Interno Bruto (PIB) (Fiesc, 2015).

Diante da importância do tema e da lacuna de estudos mencionada, o objetivo desta pesquisa é analisar como as PMC são planejadas, aplicadas e avaliadas pela PE de confecção de vestuários, haja vista que os resultados podem contribuir para o entendimento do modelo de Coviello et al. (2001) em um novo contexto. Para tanto, na sequência, será apresentada uma discussão teórica das práticas de marketing, a partir do modelo de Coviello et al. (1997, 2001), os aspectos metodológicos utilizados, a análise dos resultados e as considerações finais.

\section{REFERENCIAL TEÓRICO}

\subsection{PRÁTICAS CONTEMPORÂNEAS EM MARKETING NA PEQUENA EMPRESA}

A PE é um empreendimento de natureza privada, com pequena participação no mercado, predominantemente voltado a clientes locais, sendo o proprietário quem faz a gestão (Grimmer, Grimmer, \& Mortimer, 2018). No Brasil, essas empresas são regidas pela Lei Geral para Micro e Pequenas Empresas, com faturamento anual superior a $R \$ 360$ mil, e igual (ou inferior) a $R \$ 3,6$ milhões. Elas empregam de 10 a 49 funcionários, no caso de comércio e serviços; e de 20 a 99, na indústria de bens manufaturados (Sebrae, 2018).

Considerada como um campo propício à aplicação das PCM, a PE tem como ativo central a capacidade de oferecer ao cliente: (a) experiências orientadas por interações pessoais e sociais, estabelecendo, com isso, relacionamentos duradouros (Klemz \& Boshoff, 2001; Altinay, Saunders, \& Wang, 2014); e (b) serviço personalizado, com flexibilidade, conveniência e acessibilidade (Litz \& Stewart, 2000; Landry, Arnold, \& Stark, 2005).

A partir dos estudos seminais de Coviello et al. (1997, 2001), foi proposto o modelo conceitual de PCM, sob a perspectiva relacional, contendo as seguintes dimensões de marketing: digital, interativo e de rede. Conforme Ensslin, Sarquis, Cittadin, \& Chaves (2015) e Hoeckesfeld, Sarquis e Favretto (2017), diferentes setores de atividade, principalmente em países desenvolvidos, como Austrália e Canadá, seguem esse referencial. Além disso, há estudos voltados especificamente para algumas dessas dimensões, como a de marketing digital (Gilmore, Gallangher, \& 
Henry, 2007; Boaria, Anjos, \& Raye, 2014); de marketing de rede (Jones, Suoranta, \& Rowley, 2013; Naudê et al., 2014; Menelec \& Jones, 2015) e de marketing interativo (Eisingerich, Chun, Liu, Jia, \& Bell, 2015; Payne \& Frow, 2017).

\subsubsection{Marketing digital (e-marketing)}

Para Coviello et al. (2001), o marketing digital consiste no uso da tecnologia digital (TD) e da internet, na comunicação e em relacionamentos on-line, com grupos de consumidores identificados, buscando a customização dos serviços, a personalização do atendimento, a obtenção de negócios e a construção de interação contínua. Suryawardani e Wiranatha (2017), por sua vez, definem o marketing digital como uma prática moderna, com uso de canais eletrônicos (mídias sociais, site corporativo, marketing de conteúdo e publicidade on-line), no desenvolvimento de contato direto com clientes previamente identificados.

Nesse sentido, são exemplos de práticas de marketing digital, no contexto de PE: Google Adwords, SEO (otimização de site), e-mail de marketing, blogs, redes sociais e a integração de ferramentas digitais com o sistema de gestão de relacionamento com clientes (CRM) (Taiminen \& Karjaluoto, 2015).

Além da necessidade da avaliação periódica da eficiência operacional e dos resultados alcançados (Taiminen \& Karjaluoto, 2015; Suryawardani \& Wiranatha, 2017), Gilmore et al. (2007) alertaram que as práticas digitais precisam estar alinhadas com as estratégias tradicionais de marketing, incluindo o perfil do público-alvo, o posicionamento de mercado e as demais decisões de marketing off-line. Evidências no contexto da pequena confecção de vestuários apontam, ainda, como essenciais: a clareza para com o público-alvo, o conteúdo atualizado e a velocidade de resposta nas interações com os clientes (Colque, Baptista, \& Oliveira, 2016).

\subsubsection{Marketing de interação}

O marketing de interação consiste no uso de métodos e de táticas no relacionamento com os clientes individuais (ou stakeholders), como as constantes ações de comunicação face a face, formal e/ou informal, por meio de funcionários de linha de frente (áreas de contato interpessoal com público externo), pautadas no comprometimento e na cooperação mutuamente benéfica (Coviello et al., 2001). Essa abordagem pode também ser intermediada pela tecnologia digital/internet, constituindo vantagem competitiva para a PE, em relação às grandes organizações 
(Palmer \& Wilson, 2009). Com o avanço das novas tecnologias da comunicação (TI) e da internet (Toledo, Nakagawa, \& Yamashita, 2008), a utilização desse tipo de marketing se intensificou, haja vista o custo acessível e em tempo real, de ferramentas, como: websites responsivos, videoconferências, mídias sociais, aplicativos de armazenamento e de compartilhamento de arquivos, e dispositivos de telefonia móvel, que tornaram suas práticas mais fáceis, personalizadas e dinâmicas.

Coviello et al. (2006), em estudo empírico, no âmbito da PE, não comprovou a influência do marketing de interação sobre o desempenho da empresa, mas revelou que a dimensão de PCM é a mais utilizada no relacionamento com clientes. Reid (2008), em contrapartida, não apenas corrobora essa informação, em empresas de serviços (inclusive as de pequeno e de grande porte), como atesta sua influência positiva para o desempenho da empresa.

\subsubsection{Marketing de rede}

O marketing de rede consiste em desenvolver relacionamentos conjuntos com clientes, profissionais e/ou outras organizações do mercado, geralmente, por meio do proprietário e de gestores relevantes. A participação da empresa em redes de contatos acontece de maneira contínua, formal e informal (social), via interação pessoal (ou a distância), para buscar benefícios, como: acesso a mercados, transações comerciais, recursos e informações (Coviello et al., 2001).

Tal prática de marketing é recomendável à $\mathrm{PE}$, pois influencia em seu desempenho no relacionamento e/ou na reputação com o mercado, na aprendizagem organizacional e na troca de conhecimento (Gilmore et al., 2007; Menelec \& Jones, 2015).

No contexto da PE, Jones et al. (2013) estudaram empiricamente o marketing de rede, em mercados B2B dos EUA e do Reino Unido, desenvolvendo um modelo de gestão, com seis tipos de redes: (1) internas (de funcionários, por exemplo); (2) sociais (de amigos, parentes e conhecidos); (3) de clientes; (5) de negócios (de empresas e de indivíduos que apoiam negócios, como bancos); de inovação (de empresas inovadoras e de empreendedores criativos); e de canais de marketing (de empresas ou de profissionais do mercado que dão suporte às atividades de marketing). modelo reconhece a importância das redes de clientes nas atividades de criação ou de cocriação de valor, bem como no relacionamento da empresa com outras organizações. Estudos empíricos, no contexto da PE, indicam que o uso de PCM pode 
variar: em função do perfil do empreendedor (O'Dwyer et al., 2009; Cronin-Gilmore, 2012); do tipo de mercado (B2B ou B2C); do tipo de produto, serviços ou bens de consumo (Brodie, Coviello, \& Winklhofer, 2008; Palmer \& Wilson, 2009); e/ou do estágio de desenvolvimento da empresa (Moriarty, Jones, Rowley, \& Kupiec-Teahan, 2008; Gellinck et al., 2012).

As pesquisas de Coviello et al. (2006) e de Jones e Rowley (2011) mostram que os proprietários com orientação para o mercado tendem a ser mais inovadores; e que o marketing de rede e o marketing interativo contribuem para o desempenho da empresa. A Figura 1 apresenta uma síntese sobre as práticas de marketing digital, de marketing interativo e de marketing de rede, no contexto da PE, segundo a intenção gerencial, as características, a duração do relacionamento, o nível de execução, e os exemplos de práticas discutidas previamente.

\begin{tabular}{|c|c|c|c|}
\hline Item & Marketing Digital & Marketing Interativo & Marketing de Rede \\
\hline $\begin{array}{l}\text { Intenção } \\
\text { gerencial }\end{array}$ & $\begin{array}{l}\text { Gestão de } \\
\text { relacionamentos entre a } \\
\text { empresa e muitos } \\
\text { clientes, especialmente } \\
\text { com propósito novos } \\
\text { negócios e retenção }\end{array}$ & $\begin{array}{l}\text { Estabelecer e desenvolver } \\
\text { interações para obter } \\
\text { relacionamentos } \\
\text { cooperativos e benefícios } \\
\text { mútuos. }\end{array}$ & $\begin{array}{lr}\text { Desenvolver relações } \\
\text { no mercado para obter } \\
\text { benefícios } & \text { mútuos, } \\
\text { como acesso a novos } \\
\text { clientes e } \\
\text { comerciais. }\end{array}$ \\
\hline Características & $\begin{array}{l}\text { Utilização da tecnologia } \\
\text { da informação e da } \\
\text { internet na comunicação } \\
\text { e no relacionamento com } \\
\text { grupos de clientes.. }\end{array}$ & $\begin{array}{l}\text { Uso de métodos de } \\
\text { interação pessoal, } \\
\text { individual e social entre } \\
\text { funcionários da empresa e } \\
\text { clientes, nas diferentes } \\
\text { unidades/áreas. }\end{array}$ & $\begin{array}{lr}\text { Interação coordenada } \\
\text { de relações em rede } \\
\text { com clientes e outras } \\
\text { organizações } \\
\text { mercado, do } \\
\text { envolvendo indivíduos. }\end{array}$ \\
\hline $\begin{array}{l}\text { Duração do } \\
\text { relacionamento }\end{array}$ & $\begin{array}{l}\text { Contínua e com } \\
\text { interatividade on-line. }\end{array}$ & $\begin{array}{l}\text { Contínuo, comunicação de } \\
\text { duas vias, pessoal e on-line } \\
\text { e de curto ou longo prazo. }\end{array}$ & $\begin{array}{l}\text { Contínuo, estável e } \\
\text { dinâmica, podendo ser } \\
\text { de curto ou longo prazo. }\end{array}$ \\
\hline $\begin{array}{l}\text { Nível de } \\
\text { execução }\end{array}$ & $\begin{array}{lr}\text { Profissionais } & \text { de } \\
\text { marketing/vendas, com } \\
\text { especialistas } & \text { em } \\
\text { tecnologia. } & \end{array}$ & $\begin{array}{l}\text { Funcionários e gestores (de } \\
\text { todas as áreas e níveis } \\
\text { hierárquicos). }\end{array}$ & $\begin{array}{l}\text { Proprietário ou gestor } \\
\text { sênior da pequena } \\
\text { empresa. }\end{array}$ \\
\hline $\begin{array}{l}\text { Exemplos de } \\
\text { práticas na } \\
\text { pequena } \\
\text { empresa }\end{array}$ & 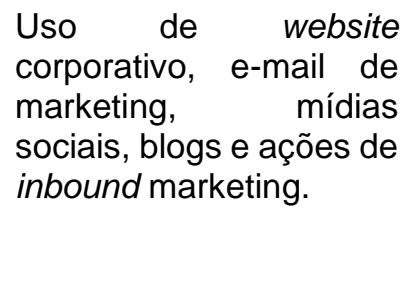 & $\begin{array}{l}\text { Interações por atendimento } \\
\text { pessoal, visita pessoal, } \\
\text { contatos por telefone, } \\
\text { websites responsivos, } \\
\text { videoconferências e redes } \\
\text { sociais (Facebook, } \\
\text { Instagram e Youtube). }\end{array}$ & $\begin{array}{l}\text { Uso de redes de contato } \\
\text { pessoal, sociais, de } \\
\text { negócios, industriais } \\
\text { e/ou canais de } \\
\text { marketing. }\end{array}$ \\
\hline
\end{tabular}

Figura 1. Dimensões das Práticas Contemporâneas de Marketing na pequena empresa Fonte: Elaborada a partir de Coviello at al. (2001) e Reid (2008).

\subsection{PLANEJAMENTO E AVALIAÇÃO DO MARKETING NA PEQUENA EMPRESA}

A PE necessita de: (a) planejamento de marketing - um dos componentes do planejamento estratégico, que compreende o processo de planejar a aplicação dos

Rev. de Empreendedorismo e Gest. Pequenas Empres. | São Paulo, v.9 | n.3 | p. 408-442 | Maio/Ago. 2020. 
recursos de marketing da empresa, de maneira a assegurar o alcance dos objetivos mercadológicos desejados (Sarquis \& Pizzinatto, 2013); (b) e da avaliação do desempenho das decisões e das práticas de marketing (Hapenciuc et al., 2015).

Pizzinatto e Silva (2009) propuseram um modelo de planejamento de marketing aplicável à PE, composto por cinco etapas: diagnóstico da situação, definição de objetivos, seleção das estratégias, elaboração de programa de ação e definição da sistemática de controle. Embora nem todas as pequenas empresas disponham de informações ou recursos necessários para cobrir integralmente essas etapas, é necessário ao menos que os componentes essenciais do plano de marketing sejam elaborados: a definição de objetivos, a seleção das estratégias de marketing e a elaboração de programa de ações (Longenecker, Petty, Palich, \& Hoy, 2018).

Alguns estudos encontraram relações positivas entre as competências de planejamento de marketing e o desempenho organizacional (como os de Hitt, Bierman, Shimizu, \& Kochhar, 2001; Pérez-Cabañero, González-Cruz, \& Cruz-Ros, 2012). Na PE, o processo de planejamento em marketing pode contribuir para melhorar: o entendimento da situação da empresa, a coordenação interfuncional para o mercado, a identificação de oportunidades e ameaças; e para ter uma seleção mais eficaz das estratégias de produtos, preços, comunicações, força de vendas e canais de distribuição.

Outro componente da gestão de marketing na PE é o processo de avaliação do desempenho (Gellinck et al., 2012), que envolve a avaliação sistemática da performance das decisões, das estratégias e das práticas utilizadas, confrontando os resultados obtidos com os objetivos esperados. Nesse tipo de organização, tal processo tem, pelo menos, duas dimensões: o modelo de avaliação e o das métricas de marketing (Carson, 1990; Brooksbank, Gerland, \& Taylor, 2008; Agus, Isa, Farid, \& Permono, 2015).

O método de avaliação compreende um conjunto de procedimentos utilizados na mensuração do desempenho de marketing, que inclui: o responsável pela avaliação; a abrangência, a periodicidade e a sistemática da avaliação; os dados/as informações; e demais recursos necessários.

As métricas de marketing compreendem as medidas/indicadores utilizadas(os) na mensuração do desempenho, como: vendas, faturamento, lucratividade, satisfação e aquisição de clientes (Coviello et al., 2006; Merrilees, Rundle-Thiele, \& Lye, 2011; Jones et al., 2013). 


\section{ASPECTOS METODOLÓGICOS}

Este estudo, classificado como qualitativo, descritivo e multicasos (Yin, 2015), teve como objeto de pesquisa três pequenas confecções de vestuários da região da Associação dos Municípios da Região Carbonífera (AMREC), no Estado de Santa Catarina (Brasil), onde predomina o setor industrial de bens manufaturados, particularmente a indústria de confecção de vestuários. As empresas escolhidas tinham pequeno porte, conforme a classificação do Sebrae (2018), realizavam investimentos em PCM, e cujos proprietários atuavam nas associações de classe da região.

Nos casos estudados, a unidade de análise é constituída pelo processo de gestão de marketing, no âmbito das práticas de marketing digital, marketing interativo e marketing de rede; sendo as fontes de informações: o proprietário, o gestor de vendas/marketing e o vendedor de loja própria, isto é, pessoas diretamente envolvidas na decisão, na execução e/ou na avaliação do desempenho de marketing.

$\mathrm{Na}$ empresa $\mathrm{A}$, foram dois entrevistados $(\mathrm{E} 1$ = proprietário e $\mathrm{E} 2$ = gestor de vendas/marketing); na $B$, três ( $E 3$ = proprietário, $E 4$ = gestor de desenvolvimento de produtos e $\mathrm{E} 5$ = vendedor de loja própria); e na C, três (E6 = proprietário, E7 = gestor de planejamento/marcas e E8 = gestor de vendas/marketing). $O$ tamanho amostral foi definido, quando se constatou que os dados empíricos coletados eram suficientes para atender aos objetivos do estudo (Glaser \& Strauss, 1967).

Foram utilizados os seguintes métodos de coleta: (a) entrevistas em profundidade - gravadas no ambiente da empresa, de maneira individualizada, elas tiveram duração média de 1 hora e 45 minutos cada e aconteceram ao longo de dois meses. Teve-se o apoio de um roteiro semiestruturado (Apêndice $A$ ), melhorado após uma validação de face com três especialistas: um diretor executivo de PE, com 12 anos na função; uma empresária e blogueira do ramo de moda, com 15 anos de experiência; e uma consultora em gestão, com 40 anos de experiência; (b) levantamento documental - a coleta de dados se pautou em materiais disponibilizados pelos entrevistados e naqueles com acesso pela internet; e (c) observação direta que envolveu o registro de evidências visuais, coletadas durante visitação pessoal às instalações e entrevistas. Os dados seguiram a técnica de análise do conteúdo, por categorização temática, sendo que, inicialmente, houve a transcrição dos depoimentos e sua validação pelos entrevistados; depois, ocorreu a pré-análise do 
material, com a leitura flutuante e a definição das regras de categorização e codificação. Para assegurar a consistência da análise qualitativa, foi utilizado o software Atlas Ti, versão 7 (Figura 2).

\begin{tabular}{|c|c|c|}
\hline CATEGORIAS & SUBCATEGORIAS & REFERÊNCIAS \\
\hline \multirow[t]{3}{*}{$\begin{array}{l}\text { Estratégias } \\
\text { contemporâneas de } \\
\text { marketing }\end{array}$} & $\begin{array}{l}\text { Marketing digital (público, objetivos e } \\
\text { práticas). }\end{array}$ & $\begin{array}{l}\text { Taiminen e Karjaluoto } \\
\text { (2015) e Coviello et al. } \\
(2006) \text {. }\end{array}$ \\
\hline & $\begin{array}{l}\text { Marketing de interação (público, objetivos e } \\
\text { práticas). }\end{array}$ & $\begin{array}{l}\text { Coviello et al (2006) e } \\
\text { Coviello et al (2008). }\end{array}$ \\
\hline & $\begin{array}{l}\text { Marketing em rede (público, objetivos e } \\
\text { práticas). }\end{array}$ & $\begin{array}{l}\text { Coviello et al. (2006) e } \\
\text { Jones et al. (2013). }\end{array}$ \\
\hline \multirow{4}{*}{$\begin{array}{l}\text { Planejamento de } \\
\text { marketing }\end{array}$} & Existência de planejamento. & \multirow{4}{*}{$\begin{array}{l}\text { Carson (1990), Gellinck et } \\
\text { al. (2012) e Sarquis e } \\
\text { Pizzinatto (2013). }\end{array}$} \\
\hline & Diagnóstico da situação. & \\
\hline & Decisão sobre objetivos. & \\
\hline & Estabelecimento de estratégias. & \\
\hline \multirow{2}{*}{$\begin{array}{l}\text { Avaliação do } \\
\text { desempenho de } \\
\text { marketing }\end{array}$} & Sistemática de avaliação. & \multirow{2}{*}{$\begin{array}{l}\text { Sarquis e lkeda (2003) e } \\
\text { Merriles (2011). }\end{array}$} \\
\hline & Métricas de desempenho. & \\
\hline
\end{tabular}

Figura 2. Categorias e subcategorias de dados analisadas Fonte: Elaborada pelos autores (2020).

\section{APRESENTAÇÃO E ANÁLISE DOS RESULTADOS}

\subsection{APRESENTAÇÃO DOS CASOS (OBJETO DE ESTUDO)}

A empresa A é uma pequena confecção de vestuários, com 28 funcionários, direcionada para mulheres de 25 a 45 anos, das classes B e C, das regiões Sul e Sudeste do Brasil, com vida social ativa e que usam artigos da moda casual. A direção geral está sob a responsabilidade do filho primogênito dos fundadores, que responde também pelas funções de marketing/vendas; a área de desenvolvimento de produtos é supervisionada por uma das proprietárias, e conta com duas estilistas; e a área de produção é coordenada pela filha do proprietário. Desde o ano de 2013, a empresa possui um profissional que apoia no planejamento e nas decisões da gestão de marketing/vendas.

A empresa $B$, também uma confecção de vestuários, tem 95 funcionários, 16 lojas próprias e 11 representantes de vendas. Sua atuação acontece nas regiões Sul, Sudeste, Centro-Oeste e Nordeste do Brasil, por meio de quatro marcas, sendo que, no ano de 2014, foi instalada a plataforma de e-commerce para uma de suas linhas de produto. A direção geral está sob a responsabilidade do proprietário-fundador; a 
área comercial, do seu sobrinho; e a área de desenvolvimento de produtos, da sua esposa e do filho.

A empresa C, outra confecção de vestuários, conta com 52 funcionários, 300 clientes lojistas e 14 representantes de vendas. Ela atende às regiões Sul e Sudeste do Brasil, por meio de duas marcas. O proprietário-fundador é o diretor geral; sua filha responde pelo marketing e pelo planejamento de uma das marcas, e tem duas designers de moda; a área comercial/vendas é coordenada por um profissional; e um dos filhos do proprietário responde pelas áreas administrativa e de produção.

\subsection{RESULTADOS DE PRÁTICAS CONTEMPORÂNEAS DE MARKETING}

\subsubsection{Marketing digital (e-marketing)}

Com relação ao marketing digital, as evidências coletadas mostram que as empresas pesquisadas investem em site corporativo, marketing em mídias sociais, catálogo virtual de produtos e e-mail marketing. Em geral, essas ações são direcionadas a clientes intermediários (lojistas) e a consumidores finais, e visam à promoção de produtos/marcas, à geração de vendas e ao desenvolvimento de relacionamentos de longo prazo. Nos três casos analisados, as ações de marketing digital são desenvolvidas por profissionais especializados no assunto (internos ou terceiros), tendo se intensificado nos três anos anteriores à entrevista (Figura 3).

$\mathrm{Na}$ empresa $\mathrm{A}$, as práticas de marketing digital incluem marketing em mídias sociais, e-mail de marketing, catálogo eletrônico de produtos, filme da coleção de produtos no YouTube e site corporativo. Os depoimentos coletados (E1 e E2) indicam que o marketing digital é utilizado para promover produtos/marcas da empresa, obter negócios, construir relacionamentos com clientes (intermediários e consumidores) e obter diferenciação competitiva. Os dados da observação direta mostram que o site da empresa é interativo e responsivo. Há, também, espaço de interatividade para os clientes, catálogo eletrônico, filme de coleção e vínculo com a fanpage da empresa nas mídias sociais. Em mídias sociais, foi evidenciada a presença no Facebook, Instagram e YouTube, com publicação de conteúdo semanal, com fotos e filmes das coleções, e catálogo de produtos. As postagens são orgânicas, sem impulsionamento, com conteúdo atualizado semanalmente, mas com baixo engajamento. A empresa envia semanalmente e-mail de marketing aos clientes, com fotos, dicas de vendas, notícias, tendências e presença em eventos. 
$\mathrm{Na}$ empresa $\mathrm{B}$, as práticas de marketing digital são: site corporativo, ecommerce, anúncios no Google Adwords e marketing em mídias sociais. Há, também, o uso de e-mail de marketing, mas com menor frequência. Depoimentos dos entrevistados (E3, E4 e E5) indicam que ações de marketing digital são dirigidas a consumidores de lojas próprias, clientes intermediários (varejistas multimarcas) e consumidores finais, e visam à promoção de produtos/marcas da empresa, à geração de vendas e à intensificação de relacionamentos com clientes. A observação direta apontou que o site institucional é interativo e responsivo, com informações sobre a empresa, as marcas e as linhas de produtos comercializadas, bem como depoimentos de clientes e a localização das lojas próprias. No Google Adwords, a empresa desenvolve anúncios de produtos/marcas e publicações. Nas mídias sociais, há uso de WhatsApp, Facebook e Instagram, com envio semanal de mensagens (informações e promoções) e imagens (fotos de produtos e lançamentos) para lojistas e consumidores finais. As postagens no Facebook e Instagram são orgânicas e têm baixo engajamento dos usuários. Já o e-commerce é direcionado apenas ao consumidor final, e comercializa a linha de acessórios em couro (bolsas, pastas e carteiras).

$\mathrm{Na}$ empresa $\mathrm{C}$, as principais ações de marketing digital são: site corporativo, marketing em mídias sociais, marketing de conteúdo, catálogo eletrônico, filmes das coleções e parcerias com blogueiras. Depoimentos dos entrevistados (E6, E7 e E8) indicam que essas ações são dirigidas a clientes intermediários (varejistas multimarcas) e consumidores finais, com a finalidade de promover produtos/marcas da empresa, estreitar relacionamentos e intensificar a comunicação com o mercado. Nas mídias sociais, a empresa utiliza WhatsApp, Instagram, Facebook, YouTube e blog. O WhatsApp é utilizado para agilizar a comunicação com os lojistas e o envio de fotos de novos produtos. Por meio do Instagram e do Facebook, mídias mais utilizadas, a empresa divulga seu catálogo virtual, ofertas, datas comemorativas e dicas de moda. Pelo YouTube, publica, principalmente, o filme das coleções.

A empresa $C$ investe, também, em filmes das coleções e os publica no site corporativo e no YouTube. Conforme o proprietário (E6), essa prática agrada aos clientes-lojistas, por facilitar a escolha de produtos/peças das coleções, e a visualização dos efeitos do vestuário no corpo de consumidoras potenciais (modelos). 


\begin{tabular}{|c|c|c|}
\hline Empr & npresa B & mpresa C \\
\hline $\begin{array}{l}\text { Público: clientes } \\
\text { intermediários (varejistas } \\
\text { multimarcas) e consumidor } \\
\text { final. } \\
\text { Objetivos: Promover } \\
\text { produtos/marcas, obter } \\
\text { negócios/vendas, construir } \\
\text { relacionamentos e obter } \\
\text { diferenciação competitiva. } \\
\text { Práticas: marketing em } \\
\text { mídias sociais (Facebook, } \\
\text { Instagran e YouTube), e-mail } \\
\text { de marketing, lookbook virtual } \\
\text { (catálogo eletrônico de } \\
\text { produtos), fashionfilm (filme } \\
\text { da coleção) e web/site } \\
\text { corporativo. } \\
\text { Ações desenvolvidas com } \\
\text { apoio de terceiros. }\end{array}$ & $\begin{array}{l}\text { Público: consumidores das } \\
\text { lojas próprias, clientes } \\
\text { intermediários (varejistas } \\
\text { multimarcas) e consumidor } \\
\text { final. } \\
\text { Objetivos: Promover } \\
\text { produtos/marcas, obter } \\
\text { negócios/vendas e } \\
\text { desenvolver relacionamentos. } \\
\text { Práticas: website corporativo, } \\
\text { e-commerce, anúncios de } \\
\text { adwords no Google e } \\
\text { marketing em mídias sociais } \\
\text { (WhatsApp, Facebook e } \\
\text { Instagran). Há e-mail } \\
\text { marketing, mas com menor } \\
\text { frequência. } \\
\text { Ações desenvolvidas com } \\
\text { apoio de terceiros. }\end{array}$ & $\begin{array}{l}\text { Público: clientes intermediários } \\
\text { (varejistas multimarcas) e } \\
\text { consumidores finais. } \\
\text { Objetivo: Promover } \\
\text { produtos/marcas, estreitar } \\
\text { relacionamentos e intensificar a } \\
\text { comunicação de marketing. } \\
\text { Práticas: website corporativo, } \\
\text { marketing em mídias sociais } \\
\text { (Whatsapp, Instagran, Facebook, } \\
\text { YouTube e Blog), marketing de } \\
\text { conteúdo, lookbook virtual das } \\
\text { coleções, FashionFilm das } \\
\text { coleções e parceria com } \\
\text { blogueiras de moda. } \\
\text { Ações desenvolvidas por pessoal } \\
\text { interno especializado no assunto. }\end{array}$ \\
\hline
\end{tabular}

Figura 3. Resumo dos principais achados sobre marketing digital Fonte: Elaborada pelos autores (2019).

\subsubsection{Marketing de interação}

Sobre o marketing de interação, as evidências coletadas indicam que as empresas estudadas investem em algumas práticas (Figura 4).

$\mathrm{Na}$ empresa A, as ações, por meio de interação pessoal, são dirigidas a clientes varejistas multimarcas e visam fortalecer as relações da empresa com os clientes. Além disso, o relacionamento pessoal com os varejistas é valorizado, e há investimentos na melhoria das interações pessoais entre os funcionários. Ademais, a empresa faz contato pessoal frequente com os gestores e os funcionários de clientes varejistas, investindo, especialmente, na visitação periódica, no atendimento pessoal e no suporte nos serviços de pós-venda.

Os dados da observação direta indicam que os gestores estimulam a interação pessoal com os clientes, acompanhando pessoalmente algumas situações. A equipe de vendas (representantes) é incentivada: a visitar os clientes, principalmente nos lançamentos de produtos; a manter contato (formal e informal) com os funcionários dos varejistas; e a sincronizar a programação de visitas com o calendário promocional dos varejistas. Segundo o gestor de vendas/marketing (E2), as ações de merchandising, no ponto de vendas, fazem parte do esforço de interação com os clientes, e incluem orientações pessoais sobre a exposição de produtos, a disponibilização de material promocional, o suporte na precificação, e o suporte aos clientes nas ações de cooperação em serviços de pós-vendas. 
$\mathrm{Na}$ empresa $\mathrm{B}$, as práticas de marketing de interação são dirigidas a clientes varejistas multimarcas e consumidores das lojas próprias, e visam ampliar o relacionamento e a lealdade dos clientes. Conforme depoimentos coletados (E3, E4 e E5), há investimento em marketing interativo, com clientes previamente identificados, por meio da manutenção de contato pessoal, envio frequente de mensagens (informações), e suporte nos serviços de pós-venda (garantia). A empresa pensa nesses clientes no processo de desenvolvimento de produtos, na escolha de canais de vendas, na contratação de vendedores e na formulação de política de pós-vendas.

Os funcionários da empresa desenvolvem contato pessoal e frequente com clientes, inclusive de maneira informal e social. Nas lojas próprias, os vendedores fazem contatos por WhatsApp, e enviam informações sobre entregas, lançamentos de produtos, promoções, aniversários, dentre outros. Conforme depoimento do vendedor de loja própria (E5), essa prática pode acontecer mais por iniciativa pessoal de alguns funcionários do que por cobrança ou incentivo dos gestores. Já nos serviços de pós-venda, a empresa busca desenvolver relacionamento cooperativo e solucionar efetivamente os problemas dos clientes. Dados da observação direta indicam que se busca esclarecer as dúvidas dos clientes, prestar atendimento cordial, e fazer troca imediata de produto com falha de produção, mesmo que seja um detalhe de acabamento.

$\mathrm{Na}$ empresa $\mathrm{C}$, as ações de marketing de interação são dirigidas a clientes intermediários (varejistas) e consumidores finais, e visam desenvolver comunicação direta, obter informações sobre os clientes e estreitar relacionamentos. As principais ações de marketing interativo são: visitação de gestores a clientes, pesquisa com consumidores no ponto de vendas e campanhas com artistas plásticos regionais. Conforme depoimentos coletados (E7 e E8), a empresa faz pesquisas de campo com consumidores de lojistas, buscando obter contato direto com eles e informações sobre perfil e percepções. Essas pesquisas são feitas semestralmente, pela gestora de planejamento e marcas, com o apoio de colaboradores da área de desenvolvimento de produtos.

Os gestores fazem visitação periódica aos principais clientes lojistas, especialmente butiques especializadas em roupa feminina e localizadas no centro da cidade, para conversar sobre a situação da loja, o mercado local, as tendências de consumo e as percepções dos clientes, desenvolvendo relações com proprietários e gestores. Segundo o gestor de vendas/marketing (E8), essa interação é frequente e 
resulta em troca de informações, envio de mensagens/fotos, resolução de problemas e na construção de laços informais e sociais com clientes.

\begin{tabular}{|c|c|c|}
\hline Empresa A & Empresa B & Empresa C \\
\hline $\begin{array}{l}\text { Público: clientes } \\
\text { intermediários (varejistas } \\
\text { multimarcas). } \\
\text { Objetivos: estabelecer } \\
\text { diálogos constantes e } \\
\text { relacionamentos } \\
\text { permanentes. } \\
\text { Práticas: visitação } \\
\text { periódica aos clientes, } \\
\text { ações de merchandising } \\
\text { no ponto de vendas com } \\
\text { clientes e cooperação nos } \\
\text { serviços de pós-venda. } \\
\text { Está em processo de } \\
\text { implantação um sistema de } \\
\text { CRM e pesquisas para } \\
\text { avaliar a satisfação dos } \\
\text { lojistas. }\end{array}$ & $\begin{array}{l}\text { Público: consumidores de lojas } \\
\text { próprias e clientes } \\
\text { intermediários (varejistas } \\
\text { multimarcas). } \\
\text { Objetivos: elevar a lealdade } \\
\text { dos consumidores e estreitar o } \\
\text { relacionamento com lojistas. } \\
\text { Práticas: contato pessoal com } \\
\text { clientes (via atendentes das } \\
\text { lojas próprias e representantes } \\
\text { de vendas), envio frequente de } \\
\text { mensagens por WhatsApp aos } \\
\text { clientes e relacionamento } \\
\text { cooperativo por meio dos } \\
\text { serviços de pós-venda. }\end{array}$ & $\begin{array}{l}\text { Público: consumidores finais e } \\
\text { clientes intermediários } \\
\text { (varejistas multimarcas). } \\
\text { Objetivos: desenvolver contato } \\
\text { direto, obter informações e } \\
\text { estreitar relacionamentos com } \\
\text { clientes. } \\
\text { Práticas: pesquisas com } \\
\text { consumidores no ponto de } \\
\text { vendas (PDV), visitação } \\
\text { pessoal aos clientes varejistas } \\
\text { pelos gestores da empresa e a } \\
\text { oferta de produtos e } \\
\text { promoções, valorizando os } \\
\text { artistas plásticos da região. }\end{array}$ \\
\hline
\end{tabular}

Figura 4. Resumo dos principais achados sobre marketing de interação Fonte: Elaborada pelos autores (2020).

\subsubsection{Marketing de interação}

Com relação ao marketing de rede, os dados coletados indicam que há, entre as organizações pesquisadas, redes de contato com outras empresas, profissionais ou entidades do mercado. Em geral, as ações de marketing de rede são executadas pelos proprietários e visam obter informação sobre o mercado, a concorrência, as tendências da moda e novas tecnologias (Figura 5).

Na empresa A, por exemplo, conforme depoimentos de entrevistados (E1 e E2), há relacionamento em rede com associações locais, em especial, por meio de parcerias e viagens para acompanhar tendências.

A empresa $B$ participa de relacionamentos em rede com associações de classe da região. Segundo o proprietário (E3), por meio dessas redes, há reuniões e eventos e se desenvolve relações com outras empresas e profissionais do mercado. De acordo com depoimentos coletados, tais redes possibilitam à empresa adquirir conhecimento técnico e informações sobre o setor, notícias da região, tendências de moda e acesso a novos clientes. O proprietário tem, também, relações pessoais com fornecedores do setor, buscando trocar referências, notícias e dados sobre o mercado.

A empresa $C$ também investe em redes de contato com associações de classe local e blogueiras. Depoimentos da gestora de planejamento/marcas (E7) confirmam 
o relacionamento do proprietário com a rede de blogueiras especializadas em moda, e a contratação para apoiar na divulgação de suas marcas e na avaliação de produtos. Por meio desses contatos, a empresa busca desenvolver relacionamentos informais e sociais, e adquirir informações técnicas sobre produtos, novas tecnologias e dados de mercado.

\begin{tabular}{|l|l|l|}
\hline Empresa A & Empresa B & Empresa C \\
\hline Redes de contato: & Redes de contato: Fiesc, & Redes de contato: Núcleo de Moda \\
Núcleo de Moda Sul & Sindvest, Núcleo de Moda Sul, & Sul Catarinense. Sindvest, Sebrae, \\
Catarinense, Sindvest & CDL, Sebrae e fornecedores. & blogueiras e pessoas influentes no \\
e Sebrae/SC. & Objetivos: adquirir conhecimento & setor da moda. \\
Objetivos: adquirir & técnico e informações sobre & Objivos: adquirir informação e \\
informação e & mercado, setor de vestuário, & mercimento técnico sobre \\
conhecimento técnico & notícias da região, concorrência, & mercácios e novas \\
sobre mercado, & tendências de moda e ter contato & tecnologias, e promover suas \\
negócio de vestuário & com lojistas revendedores de & marcas junto aos mercados-alvo. \\
e tecnologias. & vestuários. & Práticas: afiliar-se a entidades de \\
Práticas: afiliar-se a & Práticas: afiliar-se a entidades de & classe do setor e participação em \\
entidades de classe & classe do setor e participação em & eventos, palestras, feiras, rodadas \\
do setor e participar & eventos, palestras, feiras, rodadas & de negócio, viagens internacionais e \\
de eventos, & de negócio e viagens & parcerias com pessoas influentes. \\
seminários, feiras, & empresariais, ter relcionamento & \\
rodadas de negócio e & pessoal com fornecedores. & \\
viagens empresariais. & & \\
\hline
\end{tabular}

Figura 5. Resumo dos principais achados sobre marketing de rede Fonte: Elaborada pelos autores (2020).

\subsection{RESULTADOS DE PLANEJAMENTO DE MARKETING}

$\mathrm{Na}$ empresa $\mathrm{A}$, os documentos analisados revelam a existência de plano de marketing formalizado, com objetivos, metas e estratégias estabelecidas, inclusive com PCM. O planejamento é conduzido pelo proprietário, em conjunto com um profissional de mercado, com conhecimento no assunto, e há a participação do gestor de vendas/marketing e do pessoal da área de desenvolvimento de produtos. Sua elaboração é anual, juntamente com o planejamento de produtos, e considera informações coletados com vendedores próprios e representantes de vendas, durante a convenção anual de vendas.

$\mathrm{Na}$ empresa $\mathrm{B}$, os depoimentos coletados (E3 e E4) indicam haver decisões de planejamento de marketing tomadas, com objetivos, metas e estratégias; contudo, nenhum plano formal (documento) foi apresentado. No momento da análise e do planejamento, as decisões de marketing estão centralizadas no proprietário e há evidências de estratégias/ações estabelecidas de maneira emergente, a partir de decisões tomadas no dia a dia e em reação a situações momentâneas (Mintzberg, 
1987). O planejamento de marketing acontece, portanto, de maneira não sistemática, sendo também pouco estruturado e formalizado.

Na empresa C, conforme depoimentos da gestora de planejamento/marcas (E7), há um planejamento de marketing, elaborado por ela, com suporte do proprietário e do gerente de produção, baseado em dados internos e informações externas, coletadas junto aos vendedores próprios e aos representantes de vendas. Há, também, um plano de marketing formalizado, que é anual, contém uma lista de objetivos e metas definidos, bem como um conjunto de estratégias e de ações a serem implementadas. Trata-se de um plano objetivo, simplificado, e que descreve predominantemente as ações ligadas à comunicação e às vendas.

Os dados coletados indicam que as empresas pesquisadas fazem avaliação/diagnóstico da situação, quando da elaboração do planejamento de marketing; no entanto, ela não é sistemática, estruturada e abrangente, como apontado por Sarquis e Pizzinatto (2013).

$\mathrm{Na}$ empresa A, o diagnóstico de marketing é feito com base em alguns dados internos e externos. Depoimentos coletados (E1 e E2) mostram o uso de dados externos, como: Índice de Desenvolvimento Humano (IDH) por mercado, quantidade de habitantes por região, e o nível de preços, política de vendas, distribuição e produtos de concorrentes. Os principais dados internos são: volume de vendas, faturamento, recompra de clientes, clientes inativos e lucratividade. Esses dados são extraídos do sistema informatizado de gestão (ERP) e registrados em planilhas eletrônicas.

$\mathrm{Na}$ empresa $\mathrm{B}$, os depoimentos coletados indicam que esse diagnóstico é feito de maneira pouco estruturada e abrangente, e que prevalece o uso de informações provenientes da percepção (opinião) do proprietário e do gestor de desenvolvimento de produtos, especialmente em relação à situação do ambiente externo. Os principais dados internos, extraídos do software ERP, são: volume de vendas e faturamento por linha de produto, coleção e total.

A empresa C revelou fazer diagnóstico da situação, quando realiza o planejamento de marketing, utilizando tanto dados internos como externos. Os depoimentos coletados indicam o uso de dados externos sobre clientes, concorrentes e mercado (setor), em geral, fornecidos pela equipe de vendas, de observações de campo e de viagens dos gestores. Os principais dados internos são: vendas, faturamento, e lucratividade por cliente, região e representante de vendas, 
correspondentes aos últimos 12 meses. No entanto, as evidências analisadas indicam que essa avaliação é feita de maneira pouco estruturada, com foco no curto prazo (12 meses) e utiliza mais dados subjetivos e externos.

Quanto aos objetivos de marketing, as três empresas pesquisadas revelaram dispor de objetivos definidos e que investem entre 2 a $4 \%$ do faturamento anual em marketing - dado confirmado pelos demonstrativos analisados. Os atuais objetivos da empresa A são: obter posicionamento de marca desejado (ser percebida como direcionada para consumidoras da classe $B$, com idade entre 35 a 45 anos), tornar suas marcas mais conhecidas, reduzir a sensibilidade sobre o preço de suas marcas e elevar a qualidade percebida dos produtos. A empresa B visa: aumentar o volume de vendas da linha de acessórios, reduzir a sazonalidade das vendas, fortalecer suas marcas e aumentar a quantidade de lojas próprias. $E$ a empresa $C$ visa: consolidar o posicionamento de marca desejado, melhorar a sua imagem no mercado e crescer em vendas, nos próximos três anos. Ressalta-se que, nas empresas $A$ e $C$, os objetivos mencionados constam no plano de marketing apresentado.

Por fim, sobre a definição das estratégias de marketing ${ }_{2}$ as evidências indicam que essas empresas têm estratégias definidas, algumas de maneira deliberada e outras emergentes (Mintzberg, 1987). Nas empresas A e C, há várias decisões de estratégia que resultaram de um processo de planejamento de marketing (inclusive, com programação de ações, cronograma e responsáveis pela implementação), baseadas em informações de mercado e dados internos analisados. Por exemplo, na empresa $A$, as escolhas de mercado-alvo e reposicionamento de marca foram tomadas a partir da análise de dados secundários do IBGE, e de informações coletadas com consumidores finais em pontos de venda. Na empresa B, por sua vez, as evidências analisadas apontam que há mais decisões de estratégia tomadas em situações do dia a dia, de maneira reativa e com base na intuição pessoal dos dirigentes (por exemplo, a criação da linha de acessórios em couro), situação semelhante à citada por Ikeda, Campomar, \& Veludo-de-Oliveira (2007).

A Figura 6 resume os achados de planejamento de marketing nas empresas estudadas. 


\begin{tabular}{|c|c|c|}
\hline Empresa A & Empresa B & Empresa C \\
\hline $\begin{array}{l}\text { Planejamento: tem plano } \\
\text { formalizado, com objetivos, } \\
\text { metas e estratégias } \\
\text { estabelecidas. Planejamento é } \\
\text { elaborado pelo proprietário com } \\
\text { ajuda de assessor de marketing. } \\
\text { Diagnóstico: faz diagnóstico da } \\
\text { situação, mas de maneira pouco } \\
\text { sistematizada e abrangente. } \\
\text { Tem análise melhor estruturada. } \\
\text { Objetivos: posicionamento de } \\
\text { marca, tornar marcas mais } \\
\text { conhecidas, reduzir a } \\
\text { sensibilidade ao preço e } \\
\text { valorizar qualidades dos } \\
\text { produtos. } \\
\text { Estratégias: há decisões } \\
\text { deliberadas e emergentes. Há } \\
\text { mais decisoes planejadas e } \\
\text { baseadas em coleta e análise de } \\
\text { dados. }\end{array}$ & $\begin{array}{l}\text { Planejamento: plano não } \\
\text { formalizado, mas tem ciência de } \\
\text { seus objetivos e estratégias. As } \\
\text { decisões estão centralizadas } \\
\text { pelo proprietário-gerente. } \\
\text { Diagnóstico: faz diagnóstico da } \\
\text { situação, mas de maneira pouco } \\
\text { sistematizada e abrangente. } \\
\text { Utiliza dados internos e } \\
\text { informações externas. } \\
\text { Objetivos: aumentar vendas de } \\
\text { acessórios, reduzir sazonalidade } \\
\text { das vendas, fortalecer suas } \\
\text { marcas e aumentar quantidade } \\
\text { de lojas próprias. } \\
\text { Estratégias: há decisões } \\
\text { deliberadas e emergentes. Há } \\
\text { mais decisoes emergentes, } \\
\text { reativas e que resultaram da } \\
\text { intuição pessoal. }\end{array}$ & $\begin{array}{l}\text { Planejamento: tem plano } \\
\text { formalizado, mas simplificado e } \\
\text { restrito à comunicação/vendas. } \\
\text { É elaborado pela gestora de } \\
\text { marcas/planejamento, com } \\
\text { apoio do gerente de produção, e } \\
\text { tem objetivos e estratégias } \\
\text { estabelecidos. } \\
\text { Diagnóstico: faz diagnóstico da } \\
\text { situação, mas de maneira pouco } \\
\text { sistematizada e abrangente. } \\
\text { Análises mais informais e } \\
\text { baseadas no feeling pessoal. } \\
\text { Objetivos: posicionamento de } \\
\text { marca, melhorar imagem no } \\
\text { mercado e crescer em vendas } \\
20 \% \text { ao ano. } \\
\text { Estratégias: há decisões } \\
\text { deliberadas e emergentes. Há } \\
\text { várias decisões planejadas e } \\
\text { baseadas em coleta e análise de } \\
\text { dados. }\end{array}$ \\
\hline
\end{tabular}

Figura 6. Resumo dos principais achados sobre planejamento de marketing

Fonte: Elaborada pelos autores (2020).

As evidências analisadas sugerem também que as três empresas estudadas têm características de orientação empreendedora. Nelas, os proprietários evidenciaram disposição para assumir riscos, para investir em inovações e em atitudes de proatividade - características da orientação empreendedora citadas por Keh, Nguyen e Ng (2007) e Wales (2016). Na Empresa C, por exemplo, o proprietário teve disposição para assumir riscos quando decidiu entrar em novos segmentos de mercado (abordar novos públicos), investir na ampliação (diversificação) do portfólio de produtos e lançar três novas marcas, ao longo de sua história. Na Empresa B, o proprietário investe frequentemente em inovações nos produtos (como a criação da nova linha de acessórios), contratou um profissional de mercado com experiência em marketing e assumiu riscos ao desenvolver novos canais de distribuição, como a instalação do sistema e-commerce para venda direta. Na Empresa A, o proprietário manifestou características de proatividade de mercado ao relatar os esforços para promover antecipadamente mudanças nas estratégias de marketing da empresa (por exemplo, a redefinição do público-alvo e o reposicionamento da marca), quando percebeu sinais de intensificação, em momentos de crise econômica.

Há também evidências de orientação para mercado nos casos estudados, pois os depoimentos evidenciam as características de orientação para: cliente e concorrência, e interfuncional, com propósito de mercado, que correspondem ao que 
apontaram Coviello et al. (2006) e Jones \& Rowley (2011). Na Empresa A, os depoimentos coletados indicaram a preocupação dos gestores em analisar previamente o impacto das decisões de marketing nos clientes; as falas convergiram sobre o comportamento dos clientes-alvo e a preocupação interna com a satisfação e o atendimento das expectativas dos clientes, já que todos relataram também esforços para construir relacionamentos de longo prazo com clientes lojistas. A Empresa B revelou ter amplo conhecimento da concorrência, descrevendo suas características (por exemplo, forças e fraquezas) e estratégias, além de utilizar tais informações para a definição de suas estratégias de marketing. Na Empresa $\mathrm{C}$, há preocupação com a integração das áreas internas, com propósito de mercado. Por isso, ela promove mensalmente um café de integração, buscando gerar a troca de informações e coletar ideias/percepções das demais áreas. Há um gestor responsável (gerente comercial) pela integração interna com a equipe de vendas e clientes-lojistas, que participa de reuniões e projetos desenvolvidos pelas outras áreas, e procura alinhar os membros da família de proprietários quanto aos objetivos e estratégias de mercado.

A Figura 7 mostra um output do software Atlas $\mathrm{Ti}$, contendo trechos de depoimentos dos entrevistados sobre o processo de planejamento de marketing. 


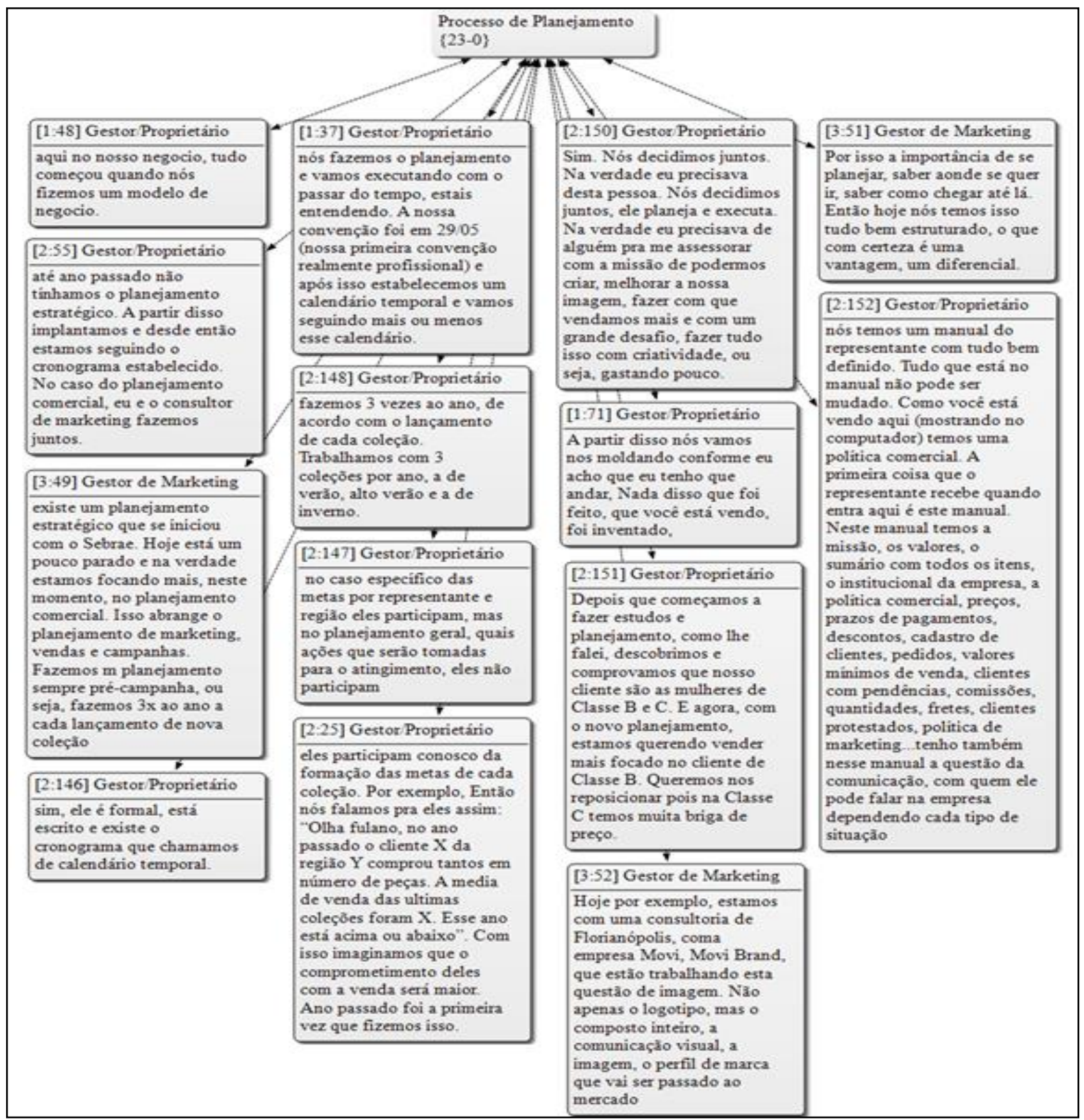

Figura 7. Depoimentos sobre processo de planejamento de marketing Fonte: Elaborada pelos autores (2020).

\subsection{RESULTADOS DE AVALIAÇÃO DO DESEMPENHO DE MARKETING}

$\mathrm{Na}$ empresa $\mathrm{A}$, conforme depoimentos dos entrevistados (E1 e $E 2)$, há uma avaliação periódica do desempenho de marketing, feita pelo proprietário, com a participação do assessor de marketing, em reuniões quinzenais, ao final de cada coleção e na convenção anual de vendas. Nela, a análise comparativa é realizada entre o desempenho obtido, os resultados da coleção passada e as metas estabelecidas. As métricas de marketing utilizadas são: volume de vendas e faturamento líquido por vendedor, linha de produto, tipo de produto, região geográfica e revendedores lojistas (principais clientes). Há, às vezes, a análise das métricas 
como taxa de recompra dos clientes, percentual de clientes inativos e lucratividade de vendas (margem bruta) por coleção de produtos. Os dados necessários são extraídos do software de gestão informatizada, tabulados em planilhas eletrônicas, e apresentados em forma de gráficos e tabelas.

Um processo de avaliação do desempenho de marketing é estruturado quando apresenta um método (procedimento) de avaliação claro, atividades/tarefas organizadas, periodicidade definida, faz análise estratificada no âmbito de produtos, vendedores, mercados e clientes, e dispõe dos recursos necessários, em termos de informações, tecnologia e competências. Assim, é possível afirmar que a Empresa $A$ dispõe de um processo de avaliação moderadamente estruturado, pois tem método claro, periodicidade definida, faz análise estratificada (por produtos, vendedores, mercados e clientes), e utiliza planilhas eletrônicas formatadas para execução das análises desejadas.

Na empresa B, conforme gestores entrevistados (E3 e E4), há uma avaliação do desempenho de marketing limitada à performance de produtos/linhas de produtos. A avaliação é feita mensalmente e ao final de cada coleção, pelo proprietário, em conjunto com gestora de desenvolvimento de produtos, estilistas e vendedores das lojas próprias. Ao final de cada coleção, ela é realizada com os representantes de vendas. Seu objetivo é analisar o desempenho atual, em relação às metas estabelecidas. Os documentos analisados indicam as métricas utilizadas: volume de vendas e faturamento líquido por linha de produto, coleção e total da empresa. Os dados necessários são extraídos do software ERP. Não há o uso de métricas detalhadas, por tipo de produto, nem por vendedor, por região geográfica e por cliente (revendedor).

As evidências analisadas sugerem que a empresa $B$ tem um processo de avaliação moderadamente estruturado, pois apresenta um método definido (compara os resultados em relação às metas estabelecidas), faz análise consolidada e estratificada no âmbito de produtos (linhas e tipos de produtos), tem periodicidade definida e dispõe de software ERP, que fornece relatórios com as informações necessárias.

Na empresa $\mathrm{C}$ os depoimentos dos gestores entrevistados (E6, E7 e E8) indicam que há avaliação do desempenho de marketing, mas ela é focada nos resultados da coleção de produtos, pois compreende a análise comparativa do desempenho obtido em relação aos meses anteriores e à coleção passada. A direção-geral se reúne 
mensalmente com a gestora de marketing, o gestor de produção e o gestor de vendas, para analisar os resultados alcançados, a partir de dados do sistema ERP. As métricas utilizadas são: volume de vendas e faturamento líquido, por coleção e total da empresa (mas ela não é detalhada por linha/tipo de produto, vendedor, região geográfica ou cliente).

Dados analisados sugerem, no entanto, que a empresa $\mathrm{C}$ dispõe de um processo de avaliação pouco estruturado, pois, embora tenha periodicidade definida e software ERP, que emite relatórios sobre o desempenho de vendas, essa avaliação é feita de maneira apenas consolidada (no âmbito geral da coleção de produtos), com organização das atividades, dados/informações sobre desempenho e conhecimento especializado no assunto em número reduzido. A Figura 8 resume os achados da avaliação do desempenho nas empresas estudadas.

\begin{tabular}{|c|c|c|}
\hline Empresa A & Empresa B & Empresa C \\
\hline $\begin{array}{l}\text { Sistemática: moderadamente } \\
\text { estruturada, detalhada e com } \\
\text { periodicidade definida. Envolve } \\
\text { análise comparativa do } \\
\text { desempenho obtido em relação } \\
\text { à coleção passada e às metas } \\
\text { estabelecidas. } \\
\text { Métricas: volume de vendas e } \\
\text { faturamento líquido por } \\
\text { vendedor, linha de produto, tipo } \\
\text { de produto, região geográfica e } \\
\text { revendedores lojistas; taxa de } \\
\text { recompra dos clientes, } \\
\text { percentual de clientes inativos e } \\
\text { lucratividade por coleção de } \\
\text { produtos. }\end{array}$ & $\begin{array}{l}\text { Sistemática: moderadamente } \\
\text { estruturada, restrita ao } \\
\text { desempenho de linhas/produtos, } \\
\text { mas periodicidade definida. } \\
\text { Envolve a análise comparativa } \\
\text { do desempenho obtido em } \\
\text { relação às metas estabelecidas. } \\
\text { Mensura também do } \\
\text { desempenho da linha de } \\
\text { acessórios comercializada pelo } \\
\text { e-commerce } \\
\text { Métricas: volume de vendas e } \\
\text { faturamento líquido por linha de } \\
\text { produto, coleção e total da } \\
\text { empresa. }\end{array}$ & $\begin{array}{l}\text { Sistemática: pouco estruturada, } \\
\text { restrita ao desempenho da } \\
\text { coleção e da empresa, e tem } \\
\text { periodicidade definida. Envolve a } \\
\text { análise comparativa do } \\
\text { desempenho em relação ao } \\
\text { histórico (outros meses e total da } \\
\text { coleção passada) e às metas } \\
\text { estabelecidas. } \\
\text { Métricas: volume de vendas e } \\
\text { faturamento líquido por coleção } \\
\text { e total da empresa. }\end{array}$ \\
\hline
\end{tabular}

Figura 8. Resumo dos achados sobre avaliação do desempenho de marketing Fonte: Elaborada pelos autores (2020).

\subsection{DISCUSSÃO E PROPOSIÇÃO DE PESQUISAS}

Os resultados sugerem que o marketing digital é a dimensão de PCM mais utilizada pelas empresas estudadas. Há o uso de práticas digitais direcionadas a clientes intermediários (lojistas) e a consumidores finais, incluindo sites corporativos responsivos, páginas em mídias sociais, anúncios no Google Adwords, catálogo virtual de produtos, e-mail de marketing e loja virtual.

A pesquisa de Targino, Urdan, \& Chauvel (2013), no Brasil, apontou somente o uso de e-mail de marketing, site corporativo e e-commerce, o que pode significar um avanço nas práticas de marketing digital das pequenas empresas. No entanto, 
conforme Colque et al. (2016), a maioria das postagens publicadas nas mídias sociais de pequenas empresas tem anúncios de produtos e carecem da criação de conteúdo para clientes. Além disso, as empresas estudadas carecem de sistema de informações de marketing e de software de CRM, ferramentas que auxiliem na gestão e na análise das práticas de marketing digital (Boaria et al., 2014).

Quanto ao marketing de interação, os achados indicam que as empresas estudadas valorizam e investem no relacionamento com clientes (especialmente varejistas), nas relações de gestores e funcionários com clientes, incluindo visita pessoal periódica, atendimento personalizado e serviços de pós-venda. Há, também, ações de interação frequente, por meio de sites e mídias sociais, como evidenciado na empresa $B$. Isso confirma o estudo de marketing de relacionamento de Targino et al. (2013): a pequena confecção de vestuários no Brasil investe em algumas práticas de marketing de interação, em geral, com propósito de estreitar relacionamentos e obter a lealdade de clientes. As ações de interação são, principalmente, direcionadas a clientes B2B, ou seja, lojistas multimarcas, conforme Coviello et al. (2001, 2006).

Há evidências de diferenças entre as práticas de marketing de grandes e pequenas empresas na literatura (Carson \& Gilmore, 2000; Gilmore et al., 2001; O'Dwyer et al., 2009; Gilboa, Seger-Guttmann, \& Mimran, 2019). Diferente do que acontece na grande empresa, onde as interações com clientes são orientadas pelo uso da tecnologia, na PE elas são mais informais e predomina o uso de relacionamento social, de serviço pessoal e personalizado, da construção de relacionamentos duradouros e de maior participação do proprietário-gerente no relacionamento com clientes.

No marketing de rede, os resultados indicam que as empresas estudadas têm relacionamentos em rede com outras empresas, profissionais e entidades do mercado, em geral, com propósito de obter informação sobre mercado, concorrência, tendências da moda e novas tecnologias (Coviello et al., 2006; Jones et al., 2013). Foi observado, também, que as redes de contato selecionadas têm proximidade geográfica, afinidade de ideias/necessidades com outros participantes e propósito de cooperação e aprendizado, características das pequenas empresas (Menelec \& Jones, 2015). Os proprietários das empresas estudadas atuam diretamente nas redes de contato, mantendo relações informais e sociais, inclusive com concorrentes (por exemplo, Núcleo de Modas) e influenciam diretamente no desempenho das ações realizadas, conforme Naudé et al. (2014). 
Com relação ao planejamento e à avaliação de desempenho de marketing, todas as empresas estudadas têm esses métodos. Há evidências de que decisões de planejamento são tomadas a partir de um diagnóstico da situação de marketing, e que há objetivos, metas e estratégias estabelecidos. O planejamento resulta em um plano formalizado (conforme as empresas A e C) e, em alguns casos, é elaborado com suporte de profissional de mercado especializado.

A avaliação de desempenho, por sua vez, acontece em periodicidade definida, e envolve a análise comparativa dos resultados alcançados em relação aos dados da coleção anterior e às metas estabelecidas, mas a sistemática utilizada é pouco estruturada (exceto no caso das empresas $A$ e B), não há métricas específicas para práticas contemporâneas de marketing (exceto no e-commerce da empresa $\mathrm{B}$ ).

As empresas estudadas não dispõem de software especializado em análise de dados, tanto no planejamento como na avaliação do desempenho; possuem limitações no processo de avaliação de desempenho, e carecem de sistemática mais aprimorada (Gellinck et al., 2012); utilizam, ainda, poucas métricas de marketing, predominantemente de desempenho financeiro (volume de vendas e faturamento) (Reid, 2008).

Os resultados deste estudo mostram que as pequenas empresas estudadas utilizam poucos canais de venda/distribuição (nelas, predomina o uso de canais offline), adotam uma abordagem simplificada no planejamento de marketing e dispõem de processo de avaliação de desempenho menos estruturado. A grande empresa tende a utilizar maior variedade de métricas de marketing e de mercado, como participação de mercado (Reid, 2008); enquanto as pequenas empesas estudadas utilizam poucas métricas de marketing, principalmente as de natureza financeiras (por exemplo, venda e faturamento).

A partir dos resultados, algumas proposições de pesquisa foram formuladas, visando contribuir para a literatura sobre o assunto. As empresas estudadas utilizam práticas de marketing interativo, marketing digital e marketing de rede, com características semelhantes ao que foi apontado por Reid (2008), na Austrália, e por Targino et al. (2013), no Brasil. No entanto, a intensidade de uso dessas práticas varia em função das orientações empreendedora e para o mercado da empresa. A orientação empreendedora está relacionada ao proprietário-gerente e à disposição para riscos, inovação e atitude de proatividade (Keh et al., 2007; Wales, 2016). Já a orientação para mercado relaciona-se com à capacidade de obtenção e disseminação

Rev. de Empreendedorismo e Gest. Pequenas Empres. | São Paulo, v.9 | n.3 | p. 408-442 | Maio/Ago. 2020. 
de informações, e responsividade de mercado (Gellink et al., 2012; Cronin-Gilmore, 2012).

Os resultados da análise dos dados sugerem que, nas empresas estudadas, as decisões de marketing são tomadas (ou fortemente influenciadas) pelo proprietáriogerente, com atitude de proatividade, disposição para assumir riscos, e investimentos em inovação, tanto de produtos como de processos. Nas pequenas empresas, cujo proprietário tem mais atitude empreendedora (empresas A e $\mathrm{C}$ ), há plano de marketing formalizado e mais decisões de estratégias deliberadas. Nelas, observa-se a capacidade de marketing, como a obtenção de informações de mercado, a disseminação interna de informações e a adaptação à demanda do mercado e às necessidades dos clientes. Isso reflete o nível de conhecimento em marketing das empresas (Hooley, Greenley, Cadogan, \& Fahy, 2005; Merrilees et al., 2011). Assim, surgiu a Proposição 1 de pesquisa: no Brasil, a pequena confecção de vestuários utiliza práticas de marketing interativo, marketing digital e marketing de rede, mas a intensidade de uso varia, conforme a orientação empreendedora e para mercado.

A tomada de decisão de planejamento de marketing ocorre a partir de objetivos, metas e estratégias estabelecidos (Pizzinatto \& Silva, 2013). Há algum diagnóstico da situação de marketing, com decisões tomadas a partir de informações internas e externas, no contexto da empresa brasileira de confecção de vestuários. No entanto, como revelado no estudo sobre planejamento de marketing, de lkeda et al. (2007), no contexto brasileiro, no diagnóstico de marketing há carência de dados (internos e externos) mais abrangentes $\mathrm{e}$ as evidências sugerem que, nas práticas contemporâneas de marketing, predominam decisões tomadas de maneira emergente e baseadas no feeling do proprietário ou dos gestores de marketing. Com isso, o processo de diagnóstico tende a ser simplificado e pouco estruturado. Diante disso, a Proposição 2 de pesquisa é: a pequena confecção de vestuários brasileira toma decisões de planejamento de marketing, mas, nas práticas contemporâneas de marketing, predomina o uso de decisões emergentes, tomadas a partir de dados pouco abrangentes e baseadas no feeling do proprietário-gerente.

Foi também identificado que a pequena confecção de vestuário brasileira faz avaliação do desempenho de marketing/vendas, inclusive com periodicidade definida, mas que utiliza uma sistemática de avaliação menos estruturada e basicamente com métricas de natureza financeira, como vendas, faturamento e lucratividade (por exemplo, as empresas B e C). Apesar da presença de práticas de marketing digital,

Rev. de Empreendedorismo e Gest. Pequenas Empres. | São Paulo, v.9 | n.3 | p. 408-442 | Maio/Ago. 2020. 
estranhamente não se observa o uso de métricas de interação ou o engajamento de usuários nas mídias sociais.

Na Austrália, a pesquisa de Reid (2008) apontou que as empresas pesquisadas fazem avaliação do desempenho de marketing, mas utilizam poucas métricas de desempenho, principalmente a lucratividade e as vendas. No caso da pequena confecção de vestuários brasileira, a justificativa pode ser o limitado conhecimento dos gestores em sistemática de avaliação e métricas de marketing, ou a ausência de recursos tecnológicos especializados, como software de extração e de análise de dados. Assim, a Proposição 3 de pesquisa formulada é: no Brasil, a pequena confecção de vestuários faz avaliação de desempenho de marketing/vendas, mas, em geral, apenas no âmbito de produtos/coleção de vestuários, utilizando poucas métricas de marketing, basicamente as financeiras, como volume de vendas, valor de faturamento e lucratividade bruta.

\section{CONSIDERAÇÕES FINAIS}

Este estudo analisou o uso das práticas contemporâneas de marketing no contexto de pequenas confecções de vestuários, em relação às dimensões: marketing interativo, marketing digital e marketing de rede, inclusive no âmbito do planejamento e da avaliação do desempenho.

Os resultados indicam que as empresas estudadas utilizam práticas de marketing de interação (por exemplo, visita pessoal periódica, atendimento personalizado e suporte de pós-venda), de marketing de rede (participação em redes de relacionamento com outras empresas, profissionais e entidades do mercado), e, principalmente, de marketing digital (sites corporativos responsivos, páginas em mídias sociais, anúncios no Google Adwords, catálogo virtual de produtos, e-mail de marketing, loja virtual e comunicação via WhatsApp), e que a intensidade dessas práticas varia, conforme as orientações empreendedora e para o mercado da empresa.

Foi identificada, também, a existência de planejamento e de plano de marketing formalizado, com objetivos, metas e estratégias estabelecidas, contendo, inclusive, algumas das práticas contemporâneas de marketing. O planejamento conta com suporte de profissional especializado (interno ou externo) e apresenta decisões tomadas, a partir de um diagnóstico da situação de marketing. No entanto, as decisões de marketing são fortemente influenciadas pelo proprietário-gerente, e há casos que 
resultam de atitude reativa, em situações do dia a dia (decisões emergentes) e que são baseadas no feeling do proprietário e de gestores de marketing.

Com relação à avaliação de desempenho, os resultados sugerem que a pequena confecção de vestuários no Brasil faz avaliação do desempenho de marketing/vendas, inclusive com periodicidade definida, mas que utiliza uma sistemática pouco elaborada e basicamente métricas de marketing de natureza financeira (vendas, faturamento e lucratividade), com exceção para o uso de e-commerce.

Dentre as contribuições do estudo, está o entendimento sobre dimensões de PCM do modelo de Coviello et al. (2001), no contexto da PE, detalhando evidências empíricas sobre o uso de marketing digital, marketing de interação e marketing de rede, no setor de confecção de vestuários no Brasil.

Este estudo possibilitou, ainda, a confirmação de achados de pesquisas sobre o tema e a formulação de proposições para futuros estudos. Além disso, foi destacado, a partir de uma visão qualitativa, como acontece o planejamento e a avaliação de desempenho de práticas contemporâneas de marketing, no contexto da PE no Brasil. Sendo assim, como direcionamento para futuros estudos, é sugerida essa mesma investigação, em outras regiões do Brasil, ou em outros ramos de atividade do setor têxtil, como roupa de cama e mesa, ou tapetes e cortinas.

Foi evidenciada, ainda, a necessidade de modelos conceituais sobre planejamento e avaliação do desempenho de práticas contemporâneas de marketing, aplicáveis à PE. Como a literatura indica que há diferenças entre as práticas de marketing das pequenas e grandes empresas, evidencia-se a relevância de ampliar a compreensão sobre essas diferenças nas empresas de confecção de vestuários, no âmbito das práticas de marketing digital, interativo e de rede.

Além disso, estudos quantitativos poderiam auxiliar na avaliação das três proposições de pesquisa formuladas, a partir dos resultados do estudo; ou analisar o impacto de práticas especificas de marketing digital, marketing de interação e marketing de rede no desempenho da PE.

\section{REFERÊNCIAS}

Agus, A., Isa, M., Farid, M., \& Permono, S. (2015). An assessment of SME competitiveness in Indonesia. Journal of Competitiveness, 7(2), 60-74. 
Altinay, L., Saunders, M., \& Wang, C. (2014). The influence of culture on trust judgments in customer relationship development by ethnic minority small businesses. Journal of Small Business Management, 52(1), 59-78.

Boaria, F., Anjos, S., \& Raye, R. (2014). A aplicação do e-marketing nas redes hoteleiras do Brasil. Tourism \& Management Studies, 10(2), 116-122.

Brodie, R., Coviello, N., \& Winklhofer, H. (2008). Contemporary marketing practices research program: a review of the first decade. Journal of Business \& Industrial Marketing, 23(2), 84-94.

Brooksbank, R., Garland, R., \& Taylor, D. (2008). Strategie marketing practices: their contribution to the competitive success of medium-sized manufacturing firms in New Zealand. Small Enterprise Research, 16(2), 8-20.

Carson, D. (1990). Some exploratory models for assessing small firms marketing performance (A qualitative approach). European Journal of Marketing, 24(11), 8-51.

Carson, D., \& Gilmore, A. (2000). Marketing at the interface: not 'what' but 'how'. Journal of Marketing Theory and Practice, 8(2), 1-7.

Colque, E., Baptista, J., \& Oliveira, C. (2016). Análise da utilização de boas práticas de marketing digital em uma rede social. Revista Fatec Sebrae em Debate-Gestão, Tecnologias e Negócios, 3(5), 114-130.

Coviello, N., Milley, R., \& Marcolin, B. (2001). Understanding IT-enabled interactivity in contemporary marketing. Journal of interactive marketing, 15(4), 18-33.

Coviello, N., Brodie, R., \& Munro, H. (1997). Understanding contemporary marketing: development of a classification scheme. Journal of Marketing Management, 13(6), 501 522.

Coviello, N., Winklhofer, H., \& Hamilton, K. (2006). Marketing practices and performance of small service firms: an examination in the tourism accommodation sector. Journal of Service Research, 9(1), 38-58. 
Cronin-Gilmore, J. (2012). Exploring marketing strategies in small businesses. Journal of Marketing Development and Competitiveness, 6(1), 96-107.

Dadzie, K., Johnston, W., \& Pels, J. (2008). Business-to-business marketing practices in West Africa, Argentina and the United States. Journal of Business \& Industrial Marketing, 23(2), 115-123.

Eisingerich, A., Chun, H., Liu, Y., Jia, H., \& Bell, S. (2015). Why recommend a brand faceto-face but not on Facebook? How word-of-mouth on online social sites differs from traditional word-of-mouth. Journal of Consumer Psychology, 25(1), 120-128.

Ensslin, L., Sarquis, A., Cittadin, J., \& Chaves, L. (2015). Evidenciação do estado da arte sobre marketing para pequenas empresas: levantamento e análise do período 2003-2013. Revista da Micro e Pequena Empresa, 9(3), 2-21.

Fiesc - Federação das Indústrias do Estado de Santa Catarina (2015). Relatório anual 2014. Recuperado de https://fiesc.com.br/pt-br/publicacoes-e-estatisticas/relatorio-anual2014-0

Gilmore, A., Gallagher, D., \& Henry, S. (2007). E-marketing and SMEs: operational lessons for the future. European Business Review, 19(3), 234-247.

Glaser, B., \& Strauss, A. (1967). The discovery of grounded theory: Strategies for qualitative research. Chicago, EUA: Aldire.

Hapenciuc, C., Pînzaru, F., Vătămănescu, E., \& Stanciu, P. (2015). Converging sustainable entrepreneurship and the contemporary marketing practices. An insight into romanian start-ups. Amfiteatru Economic Journal, 17(40), 938-954.

Hitt, M. A., Bierman, L., Shimizu, K., \& Kochhar, R. (2001). Direct and moderating effects of human capital on strategy and performance in professional service firms: A resourcebased perspective. Academy of Management Journal, 44(1), 13-28.

Hoeckesfeld, L., Sarquis, A., \& Favretto, J. (2017). Análise da produção científica sobre práticas contemporâneas de marketing. In Anais dos Seminários em Administração da Faculdade de Economia, Administração e Contabilidade - SemeAd. Universidade de São Paulo, São Paulo, SP, 20. 
Hooley, G., Greenley, G., Cadogan, J., \& Fahy, J. (2005). The performance impact of marketing resources. Journal of Business Research, 58(1), 18-27.

Gellynck, X., Banterle, A., Kühne, B., Carraresi, L., \& Stranieri, S. (2012). Market orientation and marketing management of traditional food producers in the EU. British Food Journal.

Gilboa, S., Seger-Guttmann, T., \& Mimran, O. (2019). The unique role of relationship marketing in small businesses' customer experience. Journal of Retailing and Consumer Services, 51, 152-164.

Grimmer, L., Grimmer, M., \& Mortimer, G. (2018). The more things change the more they stay the same: A replicated study of small retail firm resources. Journal of Retailing and Consumer Services, 44, 54-63.

Ikeda, A. A., Campomar, M. C., \& Veludo-de-Oliveira, T. M. (2007). Planejamento de marketing: um estudo no contexto brasileiro. Revista Base (Administração e Contabilidade) da Unisinos, 4(2), 113-125.

Jones, R., \& Rowley, J. (2011). Entrepreneurial marketing in small businesses: a conceptual exploration. International Small Business Journal, 29(1), 25-36.

Jones, R., Suoranta, M., \& Rowley, J. (2013). Strategic network marketing in technology SMEs. Journal of Marketing Management, 29(5-6), 671-697.

Keh, H., Nguyen, T., \& Ng, H. (2007). The effects of entrepreneurial orientation and marketing information on the performance of SMEs. Journal of Business Venturing, 22(4), 592-611.

Klemz, B., \& Boshoff, C. (2001). Environmental and emotional influences on willingnessto-buy in small and large retailers. European Journal of Marketing, 35(1/2), 70-91.

Kotler, P., Armstrong, G., Harker, M., \& Brennan, R. (1990). Marketing: an introduction. Englewood Cliffs, NJ: Prentice-Hall.

Landry, T., Arnold, T., \& Stark, J. (2005). Retailer community embeddedness and consumer patronage. Journal of Retailing and Consumer Services, 12(1), 65-72. 
Levitt, T. (1975). Marketing myopia. Boston: Harvard Business Review, p. 1-14, 1975.

Litz, R., \& Stewart, A. (2000). The late show: The effects of after-hours accessibility on the performance of small retailers. Journal of Small Business Management, 38(1), 1.

Longenecker, J. G., Petty, J. W., Palich, L. E., \& Hoy, F. (2018). Administração de Pequenas Empresas - lançando e desenvolvendo iniciativas empreendedoras. São Paulo: Cengage.

Menelec, V., \& Jones, B. (2015). Networks and marketing in small professional service businesses. Journal of Research in Marketing and Entrepreneurship, 17(2), 193-211.

Merrilees, B., Rundle-Thiele, S., \& Lye, A. (2011). Marketing capabilities: Antecedents and implications for B2B SME performance. Industrial Marketing Management, 40(3), 368-375.

Mintzberg, H. (1987). Crafting strategy. Boston: Harvard Business Review.

Moriarty, J., Jones, R., Rowley, J., \& Kupiec-Teahan, B. (2008). Marketing in small hotels: a qualitative study. Marketing Intelligence \& Planning, 26(3), 293-315.

Naudé, P., Zaefarian, G., Tavani, Z., Neghabi, S., \& Zaefarian, R. (2014). The influence of network effects on SME performance. Industrial Marketing Management, 43(4), 630-641.

O'Dwyer, M., Gilmore, A., \& Carson, D. (2009). Innovative marketing in SMEs. European Journal of Marketing, 43(1/2), 46-61.

Palmer, R., \& Wilson, H. (2009). An exploratory case study analysis of contemporary marketing practices. Journal of Strategic Marketing, 17(2), 169-187.

Parsons, E., Maclaran, P., \& Chatzidakis, A. (2017). Contemporary issues in marketing and consumer behaviour. Abingdon, UK: Routledge, 2017.

Payne, A., \& Frow, P. (2017). Relationship marketing: looking backwards towards the future. Journal of Services Marketing, 31(1), 11-15.

Pérez-Cabañero, C., González-Cruz, T., \& Cruz-Ros, S. (2012). Do family SME managers value marketing capabilities' contribution to firm performance? Marketing Intelligence \& Planning, 30(2), 116-142. 
Pizzinatto, N., \& Silva, D. (2009). Relação entre o planejamento estratégico e o planejamento de marketing. In Acevedo, C. R. (org.). Fundamentos de Marketing. Itu, SP: Ottoni.

Reid, M. (2008). Contemporary marketing in professional services. Journal of Services Marketing, 22(5), 374-384.

Sarquis, A., \& Pizzinatto, N. (2013). Modelo de processo de diagnóstico mercadológico para organizações de serviços de pequeno e médio portes. Revista de Negócios, 18(2), 81-100.

Sarquis, A., Hoeckesfeld, L., Cittadin, J., \& Lenzi, F. (2019). Práticas Contemporâneas de marketing na perspectiva relacional em empresas de serviços de contabilidade. Revista Contabilidade, Gestão e Governança, 22(1), 59-84.

Sebrae - Serviço de Apoio às Micro e Pequenas Empresas. Qual a receita bruta e o número de empregados para MEI, ME e EPP? Recuperado de http://blog.sebraesc.com.br/numero-de-empregados-receita-bruta-para-mei-me-epp/.

Suryawardani, I., \& Wiranatha, A. (2017). Digital marketing in promoting events and festivities. A case of Sanur Village Festival. Journal of Business on Hospitality and Tourism, 2(1), 159-167.

Taiminen, H., \& Karjaluoto, H. (2015). The usage of digital marketing channels in SMEs. Journal of Small Business and Enterprise Development, 22(4), 633-651.

Targino, L., Urdan, A., \& Agnes C., M. (2013). As práticas de marketing, entre transações e relacionamentos de empresas no Brasil. Brazilian Business Review, 10(2), 124-141.

Toledo, G., Nakagawa, M., \& Yamashita, S. (2008). O composto de marketing no contexto estratégico da Internet. Mackenzie Management Review, 3(1), 34-78.

Yin, R. K. (2017). Case study research and applications: Design and methods. Sage publications.

Wales, W. (2016). Entrepreneurial orientation: A review and synthesis of promising research directions. International Small Business Journal, 34(1), 3-15. 


\section{APENDICE A - ROTEIRO DE ENTREVISTA}

\section{SOBRE PRÁTICAS CONTEMPORÂNEAS DE MARKETING}

(Coviello et al., 2006, 2008; Jones et al., 2013; Taiminen \& Karjaluoto, 2015):

Quais as práticas contemporâneas de marketing da empresa (novos métodos ou inovações), no âmbito de produtos, política de preços, distribuição/vendas, comunicação e/ou no relacionamento com clientes? Como você enxerga as práticas de inovação da empresa, mas seja em produtos ou, mas processos? Como a empresa investe no marketing de interação com clientes? Quais as novidades introduzidas na interação com clientes/mercado? Como investe no marketing digital? Quais novidades nas práticas de marketing pela Internet? Quais os canais digitais utilizados? Quais mídias sociais utilizadas? Como investe no marketing em rede (networking)? Participa de redes de relacionamento com quais stakeholders? Participa de redes de relacionamento com quais outras empresas/organizações do mercado? Qual o propósito de suas práticas contemporâneas de marketing? Qual o público-alvo dessas práticas? Como essas práticas são operacionalizadas?

\section{SOBRE PLANEJAMENTO DE MARKETING}

(Carson, 1990; Gellinck et al., 2012; Sarquis \& Pizzinatto, 2013):

Como acontece o planejamento de marketing? Quão formal é esse planejamento? Quem participa do planejamento? Quando ocorre o planejamento? Como é feito o diagnóstico da situação de marketing? Quais os públicos-alvo? Como são definidos os objetivos/metas de marketing? Como são estabelecidas as estratégias/práticas de marketing?

\section{SOBRE AVALIAÇÃO DO DESEMPENHO DE MARKETING}

(Sarquis \& Ikeda, 2003; Merriles, 2011):

Como avalia o seu desempenho em marketing (sistemática)? Quais estratégias/táticas de marketing são avaliadas? Quem executa essa avaliação? Qual a frequência da avaliação? Quais ferramentas/recursos são utilizadas (software, metodologia)? Quais métricas/indicadores de desempenho analisados? Como você enxerga o desempenho de marketing da empresa? 